\title{
COMMUNICATION
}

Cite this: DOI: $10.1039 / \times 0 \times x 00000 x$

Received 00th January 2012,

Accepted 00th January 2012

DOI: $10.1039 / \times 0 \times x 00000 x$

www.rsc.org/

\section{Enantioselective one-pot synthesis of dihydroquinolones via BINOL-derived Lewis acid catalysis}

\author{
Peter C. Knipe and Martin D. Smith*
}

A high-yielding and diastereoselective route to biologically significant 2-aryl- and 2-alkyl-3-amido dihydroquinolones has been developed in up to 90:10 e.r. by employing a novel Lewis acidic BINOL-derived copper(II) catalyst.

The synthesis of 2-substituted dihydroquinolones (1-azaflavanones) has been the subject of increased synthetic effort following the discovery that these molecules exhibit potent cytotoxic activity against a large number of human cancer cell lines. ${ }^{1,2}$ In particular there has been growing interest in generating these structures in an enantioselective fashion. ${ }^{3}$ In addition to their notable biological profile, dihydroquinolones are competent intermediates for the synthesis of the core of the Martinella family of naturally-occurring alkaloids. ${ }^{4}$ Strategies to control asymmetry in the synthesis of dihydroquinolones have included $\mathrm{Rh}(\mathrm{BINAP})$-catalyzed intermolecular conjugate addition, ${ }^{5}$ kinetic resolution of racemic dihydroquinolones by $\mathrm{Pd}(\mathrm{SiocPhox})$-catalyzed allylation, ${ }^{4}$ enamine catalysis with amino-sulfonamides ${ }^{6}$ and hydrogen bond-catalyzed intramolecular conjugate addition of anilines. ${ }^{7-9}$

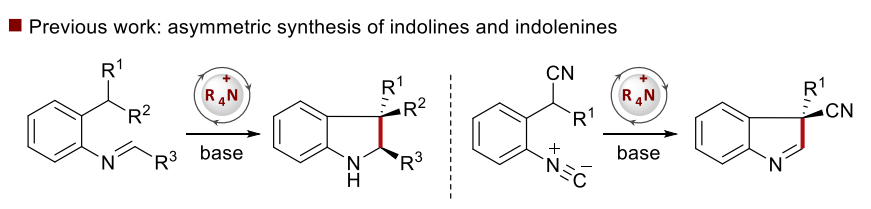

- This study: [1,6]-electrocyclization concept

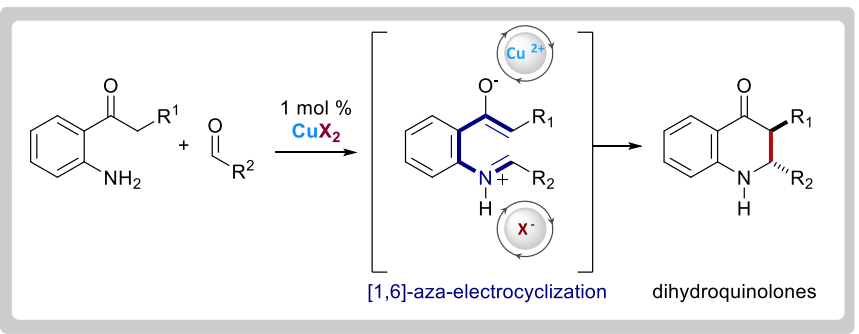

Fig. 1 Concept for asymmetric [1,6]-electrocyclization
Our ongoing studies into catalytic asymmetric electrocyclic reactions have been focused on benzylic deprotonation followed by [1,5]-azaelectrocyclization onto a pre-formed imine, under the control of a chiral counter-cation. ${ }^{10}$ This has been achieved through the use of phase-transfer catalysis, employing chiral cinchona-derived quaternary ammonium salts to mediate asymmetry, and has been used as the key step in the cascade synthesis of pyrrolizidines and indolizidines. ${ }^{11}$ We reasoned that a similar strategy could be employed in the catalysis of $[1,6]$-electrocyclic reactions by different positioning of anion-stabilizing groups (fig. 1). Our investigations began with the synthesis of aniline 1, formed in two steps from 2nitrobenzoic acid. We planned to condense the aniline with various aldehydes to allow access to the requisite imines for our study, but the poor nucleophilicity of the electron-poor aniline rendered it ineffective in this regard. Imine formation reactions under conditions previously employed ${ }^{10}$ were low-yielding and the imines were prone to hydrolysis (scheme 1).

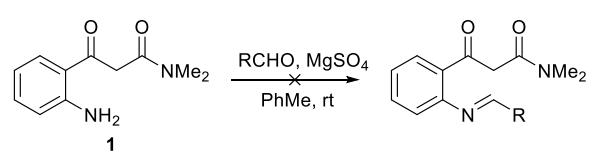

Scheme 1 Attempted imine formation.

To circumvent the problems associated with synthesis and isolation of sensitive imines we carried out both the imine formation and cyclization reactions under acidic conditions. There is precedent for such reactivity in three-component coupling reactions under both Lewis- and Brønsted-acid catalysis, as well as in intramolecular cyclization reactions. ${ }^{6,12-14} \mathrm{~A}$ screen of acids indicated that $\mathrm{Sc}^{\mathrm{III}}, \mathrm{Cu}^{\prime \prime}$ and $\mathrm{Zn}$ " trifluoromethansulfonates gave excellent conversion of amine 1 and benzaldehyde to the corresponding dihydroquinolone 2. However, chiral ligands were ineffective in achieving significant levels of enantioselectivity (table 1 , entries $5-9$ ). A range of chiral phosphoric acids were also examined (see ESI for full details); ( $R$ )-TRIP gave the best enantioselectivity, but low reaction rates made its use at cryogenic temperatures impractical (entries $10 \& 11$ ). Inspired by 
the emerging field of chiral counter-anion directed asymmetric catalysis, ${ }^{15-20} \mathrm{Cu}{ }^{11} \mathrm{~N}$-triflylphosphoramide (NTPA)-derived Lewis acid 7 was synthesized - with 3,3'-(diisopropyl)phenyl substituents chosen to reflect the most successful chiral phosphoric acid - and effectively catalysed the asymmetric process, affording the dihydroquinolone 2 in 83:17 e.r. when the reaction was carried out at $-30^{\circ} \mathrm{C}$ (entry 12). The catalyst gave both higher conversion and enantioselectivity than $(R)$-TRIP at the same temperature, and with lower catalyst loading.

Copper(II) NTPA catalyst 7 was prepared in three steps from (R)-(3,3')-bis[(triisopropyl)phenyl] BINOL. ${ }^{21,22}$ Sequential treatment of the diol with $\mathrm{POCl}_{3}$ and trifluoromethanesulfonamide provided the phosphoramide in $86 \%$ yield, and subsequent exposure to $\mathrm{Ag}_{2} \mathrm{CO}_{3}$ afforded the corresponding $\mathrm{Ag}^{\prime}$ salt, which underwent salt metathesis with $\mathrm{CuCl}_{2} \cdot 2 \mathrm{H}_{2} \mathrm{O}$ to generate $\mathrm{Cu}^{\prime \prime}$ salt $\mathbf{7}$ in $75 \%$ over two steps. $^{23,24}$

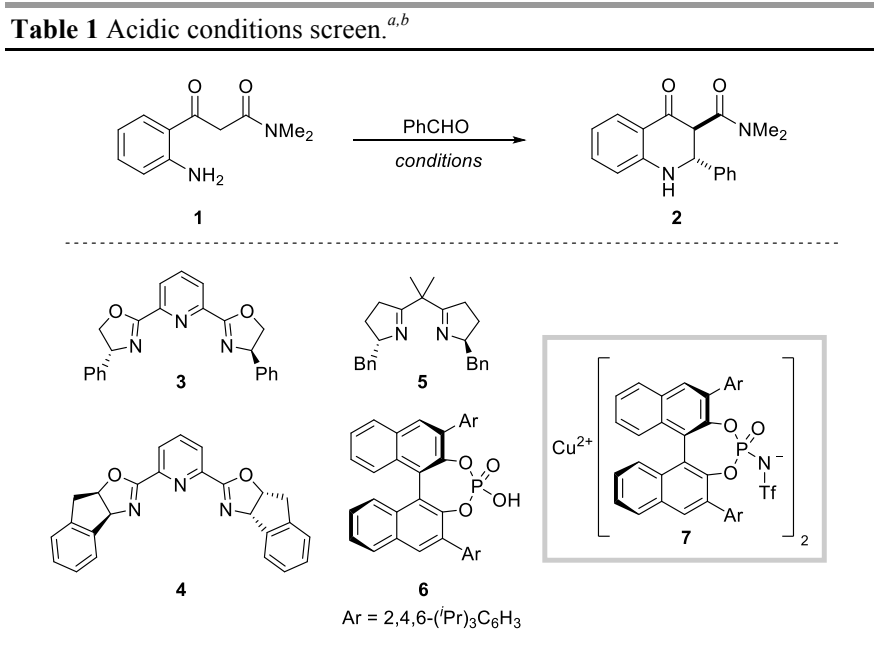

\begin{tabular}{|c|c|c|c|c|c|c|}
\hline Entry & Catalyst (eq.) & Ligand & Solvent & $T /{ }^{\circ} \mathrm{C}$ & Conv. $/ \%^{c}$ & e.r. ${ }^{d}$ \\
\hline 1 & $\mathrm{Sc}(\mathrm{OTf})_{3}(0.1)$ & - & $\mathrm{CH}_{2} \mathrm{Cl}_{2}$ & RT & $100(30 \mathrm{~min})$ & - \\
\hline 2 & $\mathrm{Zn}(\mathrm{OTf})_{2}(0.1)$ & - & $\mathrm{CH}_{2} \mathrm{Cl}_{2}$ & RT & $100(1 \mathrm{~h})$ &  \\
\hline 3 & $\begin{array}{c}\mathrm{Cu}(\mathrm{OTf})_{2} \\
\quad(0.1)\end{array}$ & - & $\mathrm{CH}_{2} \mathrm{Cl}_{2}$ & RT & $100(1 \mathrm{~h})$ & - \\
\hline 4 & $\begin{array}{c}(\mathrm{PhO})_{2} \mathrm{PO}_{2} \mathrm{H} \\
(0.2)\end{array}$ & - & $\mathrm{CH}_{2} \mathrm{Cl}_{2}$ & RT & $80(1 \mathrm{~h})$ & - \\
\hline 5 & $\mathrm{Sc}(\mathrm{OTf})_{3}(0.01)$ & 3 & $\mathrm{CH}_{2} \mathrm{Cl}_{2}$ & RT & $100(3 \mathrm{~h})$ & $50: 50$ \\
\hline 6 & $\mathrm{Sc}(\mathrm{OTf})_{3}(0.01)$ & 4 & $\mathrm{CH}_{2} \mathrm{Cl}_{2}$ & RT & $100(3 \mathrm{~h})$ & $52: 48$ \\
\hline 7 & $\mathrm{Sc}(\mathrm{OTf})_{3}(0.1)$ & 4 & 1:1 THF:PhMe & RT & $100(2 \mathrm{~h})$ & $50: 50$ \\
\hline 8 & $\mathrm{Cu}(\mathrm{OTf})_{2}(0.1)$ & 3 & 1:1 THF:PhMe & RT & $56(16 \mathrm{~h})$ & $50: 50$ \\
\hline 9 & $\mathrm{Cu}(\mathrm{OTf})_{2}(0.1)$ & 5 & 1:1 THF:PhMe & RT & $49(16 \mathrm{~h})$ & $50: 50$ \\
\hline 10 & $(R)$-TRIP $(0.05)$ & - & $\mathrm{PhMe}$ & RT & $100(4 \mathrm{~h})$ & $70: 30$ \\
\hline 11 & $(R)$-TRIP $(0.02)$ & - & $\mathrm{PhMe}$ & -30 & $50(4 d)$ & $76: 24$ \\
\hline 12 & $7(0.01)$ & - & 1:1 THF:PhMe & -30 & $100(2 d)$ & $83: 17$ \\
\hline
\end{tabular}

${ }^{a}$ All reactions were carried out employing 2 eq. benzaldehyde under the conditions indicated. ${ }^{b}$ For full catalyst screening conditions, please refer to the ESI. ${ }^{c}$ Determined by ${ }^{1} \mathrm{H}$ NMR analysis of the crude reaction mixture. ${ }^{d}$ Determined by HPLC analysis.

The optimized asymmetric reaction was then employed in the synthesis of a variety of 2-aryl dihydroquinolones (table 2). Nitrile and ester electron-withdrawing groups at the 3-position were found to be inferior in both yield and enantioselectivity to $\mathrm{N}, \mathrm{N}$-dimethylacetamide $(\mathbf{2}, \mathbf{8}$ and $\mathbf{9})$. With the exception of $\mathbf{9}$ and $\mathbf{1 3}$, yields were generally excellent, and all products were obtained as a single diastereoisomer. The trans-stereochemistry of $\mathbf{1 2}$ was verified by single crystal X-ray diffraction, with other products assumed to be trans- by analogy. ${ }^{\dagger}$ Enantioselectivities were modest, with metasubstitution generally affording the highest enantiomeric ratios within each isomeric series (e.g. 11 and 18). Electron-poor aldehydes gave better enantioselectivities than those with electron-donating substituents (10-15 vs. 16-18), yet all substituted examples gave lower selectivity than the parent benzaldehyde derivative. We attribute this to a sterically-congested substrate-catalyst complex, leading to high sensitivity to the presence of substituents.

Table 2 Scope of the reaction I: aromatic aldehydes ${ }^{\mathrm{a}-\mathrm{c}}$
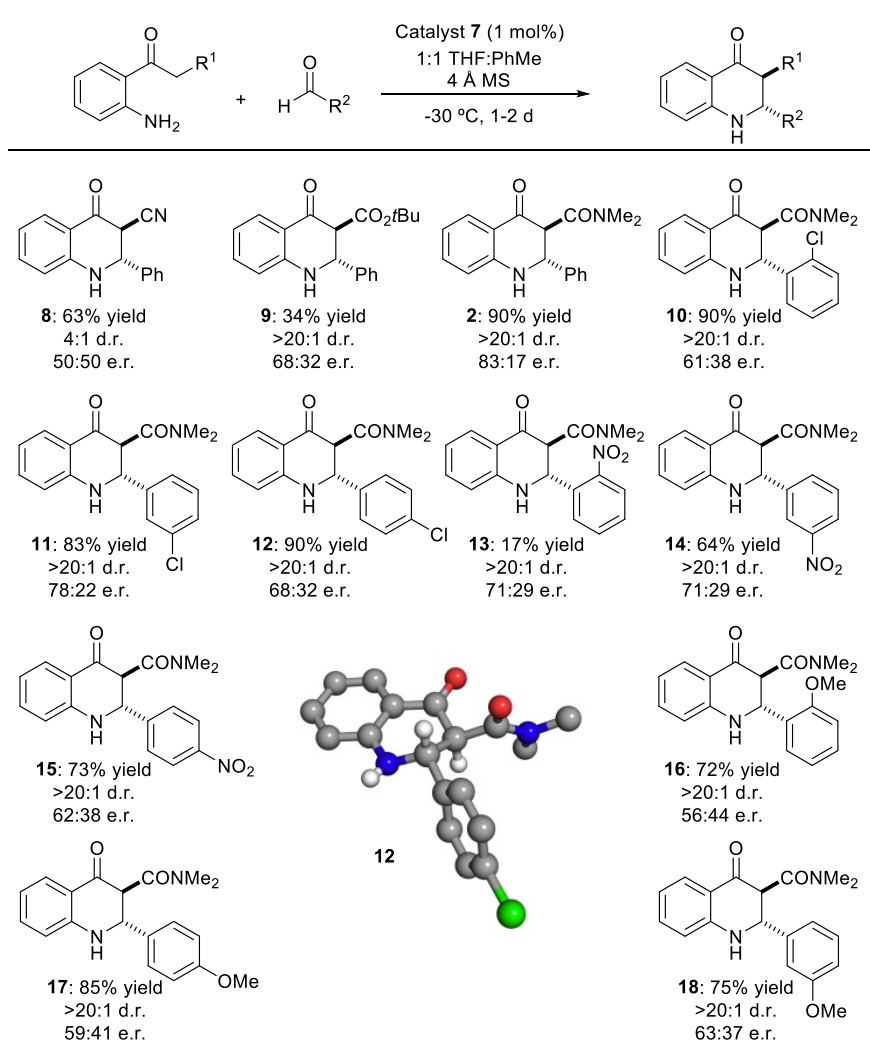

${ }^{a}$ All reactions were carried out with 2.0 eq. aldehyde and $1 \mathrm{~mol} \%$ catalyst 7 in the presence of $4 \AA \mathrm{MS}$, and were analysed after $48 \mathrm{~h} .{ }^{\mathrm{b}}$ All yields are for isolated products. ${ }^{\mathrm{c}}$ Enantioselectivities determined by chiral HPLC; diastereoselectivities determined by examination of crude 1H NMR spectra.

In general, previous synthetic efforts towards the synthesis of dihydroquinolones have focused primarily on products with aromatic substituents, and generally aliphatic substrates have garnered lower enantioselectivities. ${ }^{6-8}$ We were pleased to find that in the case of our

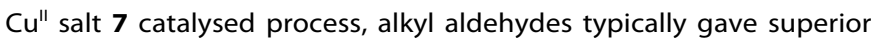
yields and enantioselectivities to the aromatic examples outlined above (table 3). 


\section{Table 3 Scope of the reaction II: aliphatic aldehydes ${ }^{\mathrm{a}-\mathrm{c}}$}

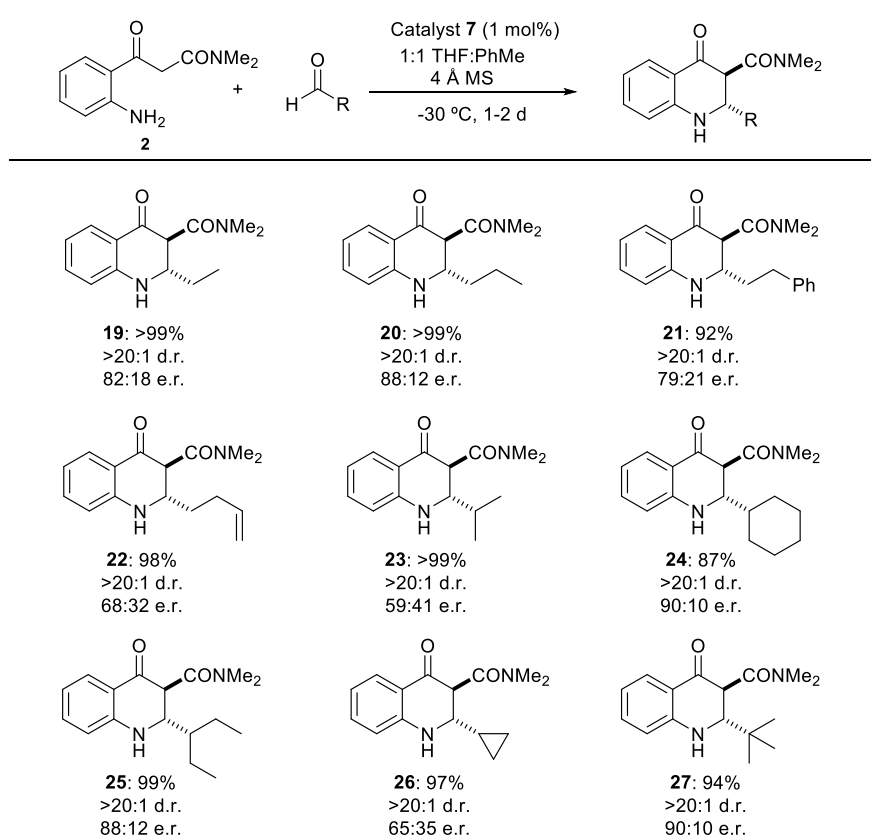

${ }^{a}$ All reactions were carried out with 2.0 eq. aldehyde and 1 mol\% catalyst 7 in the presence of $4 \AA \mathrm{MS}$, and were analysed after $48 \mathrm{~h}$. ${ }^{\mathrm{b}}$ All yields are for isolated pure product. ${ }^{\mathrm{C}}$ Enantioselectivities determined by chiral HPLC.

All dihydroquinolones were obtained in close to quantitative yields and as a single diastereoisomer. Primary aliphatic aldehydes (19-22) gave generally good enantioselectivities, with the exception of 4-pentenal derivative 22, where complexation of the alkene to the copper(II) catalyst may be a factor. Amongst the secondary aldehydederived dihydroquinolones (23-26) there was a clear correlation between size and enantioselectivity: smaller substituents (23 and 26) gave poor e.r. (59:41 and 65:35 respectively) whilst bulkier groups (24 and 25) led to much higher selectivities (90:10 and 88:12 e.r. respectively). The high enantioselectivity achieved when pivaldehyde was employed $(\mathbf{2 7}, \mathbf{9 0 : 1 0}$ e.r.) is also consistent with this trend.

It is plausible that the formation of dihydroquinolones could result either from intramolecular attack of an enolate onto an anilinederived imine, or alternatively from an initial Knoevenagel condensation followed by intramolecular 1,4-addition of the aniline. Treatment of $\alpha$-benzyl substrate $\mathbf{2 8}$ with scandium triflate successfully generated product 29, suggesting that the imine pathway is operational, since Knoevenagel condensation is not possible in this case (fig. $2 \mathrm{~A}$ ). The same product was observed to form slowly when catalyst $\mathbf{7}$ was employed, with the poor conversion (ca. $6 \%$ after $24 \mathrm{~h}$ ) likely due to the lower catalytic activity of $\mathbf{7}$ relative to scandium triflate. A mechanism for the overall transformation is therefore proposed in figure $2 \mathrm{~B}$. Coordination of copper to the 1,3dicarbonyl acidifies the a-proton; deprotonation of $\mathbf{I}$ (either inter- or intramolecular) generates copper(II) enolate-iminium species II, which upon cyclization and epimerization affords the dihydroquinolone and regenerates the catalyst. ${ }^{25}$ Whether the process constitutes an electrocyclic ring-closure or a 6-endo-trig Mannich reaction is unclear, since the expected stereochemical markers are lost in the facile epimerization of the product. ${ }^{26}$

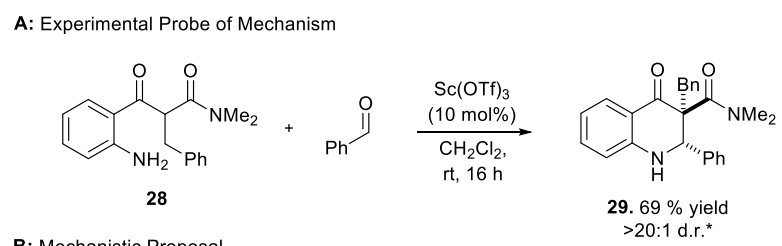

B: Mechanistic Proposal<smiles>[R]C(C)=O</smiles><smiles>[R]C1Nc2ccccc2C(=O)C1C(=O)N(C)C</smiles>

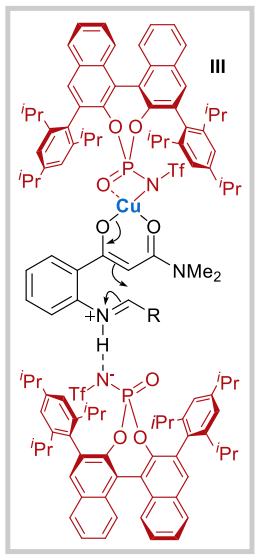

Fig. 2 Mechanistic proposal for dihydroquinolone formation.

The precise interactions that lead to asymmetric induction, and in particular the significant disparity between the enantioselectivities obtained with aromatic versus aliphatic aldehydes, remain unclear. Investigation of these interactions, and development of new catalysts designed to exploit them, may therefore be a fruitful area for further research.

\section{Conclusions}

In summary, we have developed a tandem synthesis of medicinally-relevant 2-alkyl and 2-aryl dihydroquinolones from simple substituted anilines and commercially-available aldehydes. The process is mediated by a chiral copper(II) Lewis acid catalyst derived from BINOL. Although all reactions proceeded with complete diastereoselectivity at low catalyst loading (and unusually, bulky aliphatic aldehydes were the most efficient and selective reaction partners), enantioselectivities are merely modest (at up to 90:10 e.r.). However, this mode of reaction bodes well for the application of joint metal and Brønsted acid catalysis in the synthesis of complex heterocycles.

† The European Research Council has provided financial support under the European Community's Seventh Framework Programme (FP7/2007-2013) / ERC grant agreement no. 259056. Thanks to Dr Barbara Odell and Dr Russell W. Driver for assistance with NMR and Xray crystallography respectively.

Electronic Supplementary Information (ESI) available: [details of any supplementary information available should be included here]. See DOI: $10.1039 / \mathrm{c} 000000 \mathrm{x} /$

\# The X-ray data for $\mathbf{1 2}$ have been deposited in the Cambridge Crystallographic Data Centre (CCDC 984645). 
* relative stereochemistry tentatively assigned.

1. Y. Xia, Z. Y. Yang, P. Xia, K. F. Bastow, Y. Tachibana, S. C. Kuo, E. Hamel, T. Hackl, and K. H. Lee, J. Med. Chem., 1998, 41, 11551162.

2. S.-X. Zhang, J. Feng, S.-C. Kuo, A. Brossi, E. Hamel, A. Tropsha, and K.-H. Lee, J. Med. Chem., 2000, 43, 167-176.

3. A. E. Nibbs and K. A. Scheidt, Eur. J. Org. Chem., 2012, 2012, 449462.

4. B.-L. Lei, C.-H. Ding, X.-F. Yang, X.-L. Wan, and X.-L. Hou, J. Am. Chem. Soc., 2009, 131, 18250-18251.

5. R. Shintani, T. Yamagami, T. Kimura, and T. Hayashi, Org. Lett., 2005, 7, 5317-5319.

6. H. Zheng, Q. Liu, S. Wen, H. Yang, and Y. Luo, Tetrahedron: Asymmetry, 2013, 24, 875-882.

7. X. Xiao, X. Liu, S. Dong, Y. Cai, L. Lin, and X. Feng, Chem. Eur. J., 2012, 18, 15922-6.

8. K. Kanagaraj and K. Pitchumani, J. Org. Chem., 2013, 78, 744-51.

9. X. Liu and Y. Lu, Org. Lett., 2010, 12, 5592-5595.

10. E. E. Maciver, S. Thompson, and M. D. Smith, Angew. Chem. Int. Ed., 2009, 48, 9979-9982.

11. E. E. Maciver, P. C. Knipe, A. P. Cridland, A. L. Thompson, and M. D. Smith, Chem. Sci., 2012, 3, 537-540.

12. Y.-Y. Yang, W.-G. Shou, and Y.-G. Wang, Tetrahedron, 2006, 62, 10079-10086.

13. Q.-X. Guo, H. Liu, C. Guo, S.-W. Luo, Y. Gu, and L.-Z. Gong, J. Am. Chem. Soc., 2007, 129, 3790-3791.

14. J. Zhou, Chem. Asian J., 2010, 5, 422-34.

15. M. Rueping, A. P. Antonchick, and C. Brinkmann, Angew. Chem. Int. Ed., 2007, 46, 6903-6906.

16. P. de Armas, D. Tejedor, and F. García-Tellado, Angew. Chem. Int. Ed., 2010, 49, 1013-1016.

17. Z. Shao and H. Zhang, Chem. Soc. Rev., 2009, 38, 2745-2755.

18. J. Lacour and D. Moraleda, Chem. Commun., 2009, 7073-7089.

19. M. Rueping, R. M. Koenigs, and I. Atodiresei, Chem. Eur. J., 2010, 16, 9350-9365.

20. A. Parra, S. Reboredo, A. M. Martín Castro, and J. Alemán, Org. Biomol. Chem., 2012, 10, 5001-5020.

21. D. Nakashima and H. Yamamoto, J. Am. Chem. Soc., 2006, 128, 9626-9627.

22. M. Klussmann, L. Ratjen, S. Hoffmann, V. Wakchaure, R. Goddard, and B. List, Synlett, 2010, 2189-2192.

23. G. L. Hamilton, E. J. Kang, M. Mba, and F. D. Toste, Science, 2007, 317, 496-499.

24. V. Rauniyar, Z. J. Wang, H. E. Burks, and F. D. Toste, J. Am. Chem. Soc., 2011, 133, 8486-8489.

25 It is also possible that imine formation occurs subsequently to the generation of the copper enolate.

26. R. B. Woodward and R. Hoffmann, J. Am. Chem. Soc., 1965, 87, 395-397. 